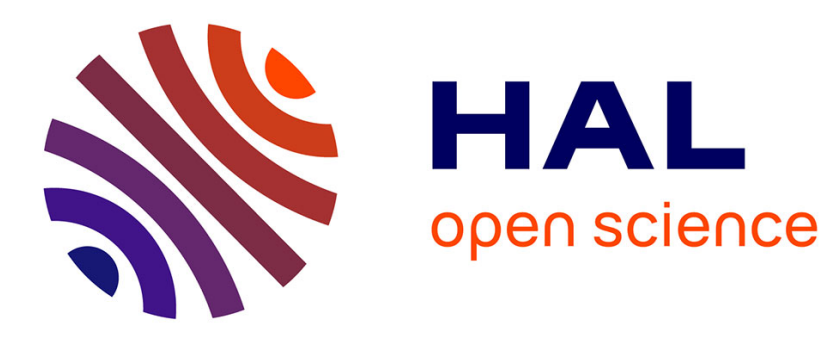

\title{
Enhancing Access to eLearning for People with Intellectual Disability: Integrating Usability with Learning
}

Theja Kuruppu Arachchi, Laurianne Sitbon, Jinglan Zhang

\section{- To cite this version:}

Theja Kuruppu Arachchi, Laurianne Sitbon, Jinglan Zhang. Enhancing Access to eLearning for People with Intellectual Disability: Integrating Usability with Learning. 16th IFIP Conference on Human-Computer Interaction (INTERACT), Sep 2017, Bombay, India. pp.13-32, 10.1007/978-3319-67684-5_2. hal-01678481

\section{HAL Id: hal-01678481 \\ https://hal.inria.fr/hal-01678481}

Submitted on 9 Jan 2018

HAL is a multi-disciplinary open access archive for the deposit and dissemination of scientific research documents, whether they are published or not. The documents may come from teaching and research institutions in France or abroad, or from public or private research centers.
L'archive ouverte pluridisciplinaire HAL, est destinée au dépôt et à la diffusion de documents scientifiques de niveau recherche, publiés ou non, émanant des établissements d'enseignement et de recherche français ou étrangers, des laboratoires publics ou privés.

\section{(c)(1)}

Distributed under a Creative Commons Attribution| 4.0 International License 


\title{
Enhancing Access to eLearning for People with Intellectual Disability: Integrating Usability with Learning
}

\author{
Theja Kuruppu Arachchi ${ }^{1,2(\bowtie)}{ }^{\text {, Laurianne Sitbon }}{ }^{1}$, Jinglan Zhang ${ }^{1}$ \\ ${ }^{1}$ Science and Engineering Faculty, Queensland University of Technology, \\ Queensland, Australia \\ theja.kuruppuarachchi@hdr.qut.edu.au, \\ \{laurianne.sitbon, jinglan.zhang\} @qut.edu.au \\ ${ }^{2}$ Main Library, University of Ruhuna, Sri Lanka \\ tka@lib.ruh.ac.lk
}

\begin{abstract}
Learning can provide people with Intellectual Disability (ID) extended learning opportunities in using information technology, thus potentially increasing digital inclusion. In order to make this a motivating experience, designs of eLearning are required to be compatible with their cognitive abilities. It is as yet unclear how to design an engaging eLearning environment that integrates usability with learning. This paper aims to explore the applicability of learning theories along with usability guidelines in designing an eLearning environment for people with ID. We discuss psychological theories on teaching and learning, and literature on challenges and opportunities of eLearning for people with ID. Based on that understanding, we present guidelines that integrate different learning theories with eLearning, for learner centered interaction design of eLearning modules for people with ID. We present a case study of applying these inclusive design considerations to an eLearning module about health information access.
\end{abstract}

Keywords. Accessibility and usability $\bullet$ Inclusive design $\bullet$ People with intellectual disability $\bullet$ eLearning $\bullet$ Human computer interaction $(\mathrm{HCI})$

\section{Introduction and Background}

Working with the Internet has been identified as a motivating involvement in digital participation among people with Intellectual Disability (ID). The Internet supports its user to be independent. Hence, as noted by Harrysson et al., the opportunity to use the Internet creates a "smart and awesome" episode for people with ID [1]. However many still experience difficulties when interacting with the Internet and accessing information. Rocha et al. reported that people with ID are able to increase their ability to navigate the Internet, provided that they receive continuous training [2]. Hence, the introduction of training programs on Internet access, for people with ID, is set to support them to improve and maintain their ability to engage with the Internet [3]. According to Sitbon et al., "satisfying an information need may act as a motivator to encourage users to develop skills they may not otherwise be interested in developing" [4]. We aim 
to develop an accessible eLearning module that teaches people with ID to access online health information. This provides the opportunity to learn skills to use the Internet in an eLearning platform, while interacting with a computer and the Internet, in a motivating, learning environment [5].

eLearning also has the potential to support a learner to practice skills to use the Internet in context. eLearning, as the term itself denotes, is learning facilitated with technology [6]. eLearning delivers instruction using a web-based medium, for the learner to access remotely. In an eLearning platform, the learner uses the Internet to navigate through learning materials. eLearning allows the learner to practise at their own pace with adequate support [7]. The opportunity to learn skills to use the Internet, in an eLearning platform provides the learner with an appropriate environment for practising such skills. According to Kolb's experiential learning theory, which emphasises learning from experience, learning is a process "whereby knowledge is created through transformation of experience" [8]. Knowledge results from the combination of grasping and transforming experience. Hence, we posit that eLearning platforms best fit with such learning situations as improving skills to use the Internet.

Designing an eLearning module for people with ID needs to consider the learner's specific abilities and context. Version No. 031 of The Victorian Intellectually Disabled Persons Services Act 1986 defines intellectual disability thus:

"intellectual disability in relation to a person over the age of five years, means the concurrent existence of - (a) significant sub-average general intellectual functioning; and - (b) significant deficits in adaptive behaviour -each of which became manifest before the age of 18 years" [9].

Intellectual disability is different from "Learning Disability". According to official definition adopted by the Learning Disabilities Association of Canada January 30, 2002 , learning disability is generally referred to as "a group of disorders, presumed due to central nervous system" [10]. In this paper, we investigate how to address the conceptual needs of people with ID, beyond the needs of people with learning disability. The main focus of the process of designing eLearning modules for people with ID should be guided by minimising the cognitive capacity required by the learner to interact with the system and the content in order to maximise the cognitive resources available for the learning process [11]. The eLearning designs should be usable and accessible to them.

eLearning designs should address the cognitive capacity, different abilities and needs of people with ID. Web accessibility has been outlined to ensure that "people with disabilities can perceive, understand, navigate, and interact with the web"[12]. Learning theories have suggestions on designing learning materials, considering the learner situation. The literature suggests that it is important to consider existing usability guidelines and learning theories together, in order to increase the accessibility, usability, and pedagogical values of eLearning designs [13], and offer the learner a motivating learning environment [14]. Learners with ID have not been included in most of the designs and the online collaborations present in the typical eLearning designs presently available. eLearning designs should allow people with ID to learn at their own pace. Most of the currently available eLearning approaches are knowledge driven. They 
aim to teach subject knowledge such as mathematics [15], languages and communication. Practice driven eLearning aims to support the learner to improve abilities through continued practical activities, such as practising skills to use computers and the Internet. Having on-site support persons, such as tutors, presents additional opportunities to develop the learner's education potential in eLearning [7]. The availability of such support people is often critical, and should be embedded in the design. The paucity of research on designing these types of eLearning for the people with ID, led us to investigate designing a motivating, rich eLearning experience for learners with ID. Addressing the gap in the literature, around eLearning design guidelines that integrate existing usability principles with strategies from learning and pedagogical psychology, this paper contributes a set of new guidelines that can be applied to a learner-centered interaction design of eLearning modules for people with ID.

In the forthcoming section, section 2 of this article, we review studies on challenges and opportunities of eLearning for people with ID. In section 3, we discuss psychological theories on teaching and learning, which will be used to understand design considerations for an eLearning module for people with ID. Then, we present a theoretical view of the interactions in an eLearning environment for people with ID in section 4. In section 5, these are incorporated in a functional model for eLearning design that integrates learning theories. Then we further integrate the identified learning theories into a theoretical framework of design guidelines for learner centered interaction design of eLearning environments for people with ID. Section 5 ends with a presentation of new design guidelines, which reflect the usability requirements as well as the pedagogical requirements of an eLearning environment for people with ID. In section 6, we present an application of these guidelines in a case study that develops a prototype of an eLearning module for people with ID.

\section{2 eLearning for People with Intellectual Disability}

Information and communication technology (ICT) empowers people with ID. Although people with ID experience difficulties in meeting demands of day-to-day life compared to others [16], they can be supported to increase their capacity to be included in society by adjusting the environment, allowing them to experience, acquire and improve their abilities.

Renblad explored the views of people with ID on their experience with ICT and empowerment [17]. The study employed qualitative methods of data collection; study of original sources of groups' reports from a conference, participant observation and interviews. The study reports that information and communication technology increases the opportunities for people with ID to be involved in social relationships and make decisions. Opportunity to use technology in eLearning adds motivational value to the learning environment that leads to a better learning experience [14]. Hence, the eLearning module we design aims to empower people with ID to be included with the Internet and use online health information, which will be a support for them to look at their health issues with confidence. 
Wong et al. explored ICT training needs among people with ID, with reference to their competency of using human computer interfaces [3]. A total of 57 people with mild or moderate intellectual disability, aged between 14 and 17 years participated in the study. Researchers identified that Microsoft's Internet Explorer (IE) was the most popular web browser among the participants, and that the most popular activities were exploring websites, searching with Yahoo, and working with bookmarks, as well as using the print and save functions. They defined three task categories: general, hardware related, and software related. Software-related tasks were to "start web browser, close web browser, explore websites, respond to dialog box, use customised bookmarks, add book marks, take printouts, save website, open saved website and use search engine". According to the performance of participants in the assigned tasks, the researchers concluded that the training programs for people with ID should be twofold: basic training associated with improving basic computer skills among low-performance groups, and advanced training on essential functions, including "orientation and attention" on the Internet. As Wong et al. noted, learning programs on computer skills designed for people with ID should be ability-specific.

Ogunbase designed a Web-Based Learning Environment (WBLE) model, and studied the effect of the learner's culture on their engagement with the learning environment [18]. According to the study, Ogunbase reported that the use of WBLE among African and European learners had been affected by different learning cultures shaped by their cultural background. Ogunbase highlights the need to consider cultural issues, in order to design WBLEs effectively. Hence, eLearning environments for people with ID should incorporate their cultural values.

For strengthening the interactions of people with ID with the learning environment, eLearning modules should be designed in conference with learning theories. Seo and Woo developed 'Math Explorer', a multimedia computer assisted instruction program for teaching mathematics for elementary level students with learning disabilities [15]. In the test for acceptance of the interface features, they identified three types of critical user interface design features: "instruction driven, manifest structure and adaptive interaction interfaces". One of the instruction driven features they identified was to introduce the subject content in small amounts. The other instruction-driven feature was to use visual representations, animations and graphics to provide an attractive and motivating experience. Manifest structure interface features were to "maintain simplicity and consistency", use "appropriate fonts and colours", and to highlight and colour-code the current tasks. Researchers utilised adaptive interaction interface features to provide feedback adaptive to student performance, and to support them with adaptive multimedia. According to the user study, Seo and Woo concluded that specific interface design guidelines should be incorporated in designs of computer assisted teaching programs, considering the capacity of the short-term memory of the students with learning difficulties.

Following a "community based ICT training program" for people with ID, Li-Tsang et al. conducted a study to identify additional support needed [19]. The interview with the participants of the training program and their caregivers showed that while the training program had increased the participants' interest in using computers, there remained 
the need for continued training on Internet use, with close support. Bunning et al. investigated the teachers' interaction with students with ID during eLearning [20]. They studied five single cases with severe intellectual disability, aged 11- 18 years, using video ethnography. The study showed that teacher interaction supported the learner to increase their motivation to learn. Heath et al. reported that it was encouraging for the learner to have closer interaction with the teacher, who encouraged them with signposts "you do it, you have a go", with nonverbal behaviours, looking at the child and pointing at the screen, and then with movements prompting initiation of action. The study concluded that, on-site teacher interaction, as a mediator of eLearning, was a support for students with ID to execute learning activities better.

Together these studies indicated that eLearning environments for people with ID could create a motivating learning experience, when designed according to the learning theories attending to their specific needs.

\section{$3 \quad$ Pedagogical Approaches for Learner Centered Design}

Designing eLearning environments for people with ID is a complex process. eLearning design should devote attention to well-defined learning tasks as well as the usability of learning interfaces [21] that address leaners' needs and learning patterns [18]. Learning theories guide the design of motivating learning environments. eLearning modules need to be developed referring to the learning theories, so the contents and the presentation are psychologically appropriate to the learner' status quo.

The learning and teaching principles reported from decades of research and practice belong to three commonly accepted learning theories: behavioural theory, social cognitive theory and constructivist learning theory [22]. Different theorists describe different points relevant to teaching and learning situations. One single theory cannot address everything to be considered in a particular educational setting. Schunk states that it is necessary to "be eclectic" and use a blend of theories to address a learning situation [23]. Similarly, the American Psychological Association's Board of Educational Affairs used psychological principles belonging to these three theories, to define fourteen learner-centered psychological principles that provide a learner-centered approach for educational designs at schools [24]. Our contribution in this article is selecting the principles that are relevant and integrating them with eLearning design guidelines.

\subsection{Behavioral Learning Theory}

Behavioural theory explains the effect of external stimulators and inhibitors on the individual's behaviour. Skinner's theory, operant conditioning, clarifies learning as a behaviour to obtain or avoid the consequences that follow [25]. Accordingly, positive reinforcements can be incorporated in eLearning designs to encourage the learner to be engaged. Skinner's approach to achieve this is to define clear goals of instruction, sequence the subject content logically, allow learner's pace of learning, and provide im- 
mediate feedback for the learner's performance. Each phase is designed to be appropriately small enough and to include subject content that prepares the learner for the next phase, and supports the learner to complete the tasks at optimal speed [26].

\subsection{Social Cognitive Theory}

Social cognitive theory focuses on interactions of behavioural and personal factors with social settings. It explains that learning behaviours could be inspired through observing and imitating a model [22]. Hence, cognitive theory describes learning as an internal process in which the learner uses his memory, thinking reflection, abstraction and metacognition skills. Bandura described learning behaviour as a result of interactions among these three factors; personal characteristics, behavioural patterns and social environment [27]. According to Bandura, personal characteristics relate to beliefs about the ability to carry out learning tasks. Hence, clear goals and reduced anxiety support a better learning experience. Considering the learners' working memory capacity, subject content should be presented in appropriate amounts, and in sequence. Learning tasks should not overload the learners' working memory [28]. The learner must be supported to make memory links between new experiences and some related information from long-term memory. Hence, designs for eLearning should accommodate functions with familiar examples that increase the learners' ability to complete given tasks.

According to social cognitive theory, personal and behavioural factors dominate the environmental factors, in determining the learning behaviour. Bandura describes this concept as personal agency, which relates to the habit of self-controlled and self-regulated learning. The learner's preference for self-regulation suggests the need of endowing eLearning modules with choices for the learner according to their learning needs.

Online learning designs should include information in small amounts, and provide opportunity to link new knowledge with existing knowledge, and apply it in real life. Allowing for learner choice creates positive thinking to engage with learning activities.

\subsection{Constructivist Learning Theory}

Constructivism describes the nature of learning; how people develop as meaningful learners. It involves the learner' process of understanding how to perform a task according to a previous experience. Bruner described this type of learning as discovery learning [29]. According to Schunk, constructivist learning environments are designed for "meaningful learning" [23]. Teacher's involvement supports the learner to experience the topics in multiple perspectives.

Brooks and Brooks described five principles with reference to constructivist learning environments [30]. The first principle is to incorporate teaching lessons that "seek and value learners' points of view". It suggests the importance of considering the learners' perspectives when designing learning environments. Constructivist learning environments not only identify the learner, but also address them. Hence, a constructivist learning environment acknowledges relativity, talks to and with the learner, gives op- 
portunity to express the learners' point of view, follows up with the learner's elaboration, and accounts for "interesting ideas" instead of grouping into "right" and "wrong" [30].

The second principle puts forward that constructivist learning environments are developed around primary concepts and "big ideas". Instead of presenting the curriculum in separate subtopics, the use of a holistic approach supports the learner to understand how the concepts relate as a whole [30]. Subject concepts for the eLearning module needs to be integrated with the holistic aim of supporting the learner. Structuring eLearning about online information seeking around "big ideas" and broad concepts supports the learner to understand multiple access points to the subject content.

According to the third principle, constructivist learning environments are designed to address the learners' suppositions. Learning activities are designed so that they support the learner to develop their skills, either consistent with, or counter to, the learners' beliefs. Cognitive, social and emotional demands of the learning materials are matched with the learner's abilities [30]. Brooks and Brooks' functional principles; "posing problems emerging relevance, structuring learning around primary concepts, and seeking and valuing students' points of view", assist curriculum designs that value student suppositions.

The fourth principle mentions that constructivist learning environments pose problems in emerging relevance. Relevant subject content is identified by probing pre-existing learning needs. An alternative strategy is to stimulate the learner's interest by allowing them to recognise the value for life [30].

The fifth principle deals with assessments, and declares that constructivist learning environments "assess student learning in the context of daily teaching". Instead of the true - false and multiple choice questions, constructivist learning environments conduct assessments by providing the learner the opportunity to demonstrate acquired skills, or to describe or discuss the learned topics in terms of value for their life [23]. This is used as a nonjudgmental feedback process between learners themselves and the instructor [30]. This type of assessment focusses on the next step after student feedback, that encourages teacher to consider redesigns for learning activities. [23].

These learning theories, that are defined in three contexts: the learner behaviour (Behavioural learning theory), the learner's cognitive process (Social cognitive theory), and learning as an experience and learner development (Constructivist learning theory), can collectively be considered when designing eLearning environments.

\section{$4 \quad$ Interaction Design and eLearning}

Anderson describes six forms of educational interactions in online learning: studentstudent interactions, student-content interactions, student-teacher interactions, teachercontent interactions, teacher-teacher interactions, and content-content interactions [28]. Garrison states that the interactions among learners, subject content and the teacher, in online learning provide a connective and collaborative learning environment [31]. The theory of online learning interaction presented by Anderson suggests the possibility of 
substituting various forms of student interactions for each other, depending on the situations that matter ("costs, content, learning objectives, convenience, technology used and time availability"), without affecting the quality of learning. According to Anderson, maintaining an extensive mastery of one of the three forms of interactions is sufficient for successful learning [32]. However, in learner-centered design of eLearning, the value of learner-interface interaction cannot be discounted [11, 15, 33-35].

\subsection{Interactions in eLearning}

In an eLearning environment, the learner interacts directly with the interface to maintain the other interactions: with the teacher, with the content and with other students. Hence, we propose that interaction design of eLearning should consider four additional interactions: content-interface, learner-interface, teacher-interface, and interface- interface (Fig. 1).

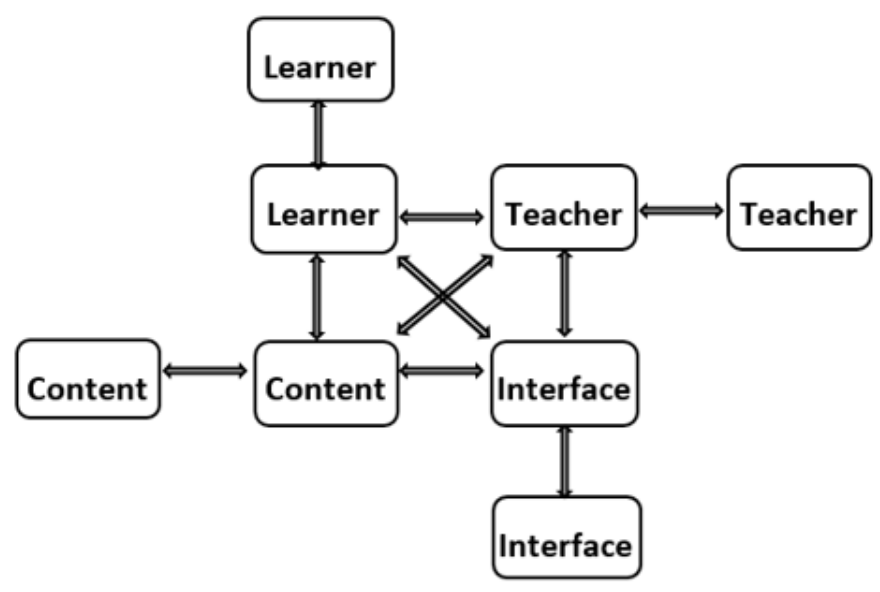

Fig. 1. A generic model of Interactions in eLearning

Learner-Interface Interaction. The learner interacts with the interface to access learning material, to submit completed activities, discuss with peers and the teacher. The learners can read each others' discussion threads and post replies. Interface supports the learner to save and print the subject content as well as discussion pages.

Content-Interface Interaction. Content-interface interaction creates an opportunity to present the subject content in appropriate formats and in accessible amounts. It acts as the medium for instruction display. The content can be presented with readable font size, acceptable colours, relevant visual images, and concept maps. The presentation of content can be facilitated with audio and video descriptions. 
Interface-Interface Interaction. Interface-interface interaction focuses on organisation of the eLearning module. It allows the learner to navigate between the subject content list, discussion threads, assessments and personal account from any page. The presentation of repetitive functions consistently in appropriate places of each page, supports the learner to navigate between pages and perform functions using a reduced amount of working memory.

Teacher-Interface Interaction. Teacher-interface interaction provides space for the teacher to introduce the module, present subject content, give announcements, introduce links to further reading, and clarify technical issues and assessment procedures.

A major factor that needs to be considered when designing an eLearning module that encourages these types of interactions is how to increase the learner's motivation. As pointed out by Li-Tsang et al., [19], people with ID need close support when learning digital skills. We propose that such context can include a tutor, who supports the leaner on-site. The tutor interacts with the learner and the eLearning interface, thus adding the following interactions to the model.

Tutor- interface Interaction. The eLearning module for people with ID should include an additional tutor interface, with which the tutor directly interacts to support the learner by personalising the interface according to the learner preferences: font size, colours, level of challenge etc. Furthermore, the tutor may clarify welcome messages as well as help pages.

Tutor- Learner Interaction. The tutor interacts with the learner to support them to perform learning tasks, provide additional concrete examples from their day-to-day life, and clarify wording of the module where appropriate.

\section{$5 \quad$ Integrating Usability with Learning}

An eLearning module that maintains the above mentioned interactions performs four main functions: delivering subject content, sharing feedback and support, performing assessments, and providing the platform/interface. Instructional strategies should be carefully chosen to design these functions to motivate the learner and to make them relevant to the learner. We developed a functional model for better understanding of the applicability of learning theories in eLearning designs (Fig. 2). 


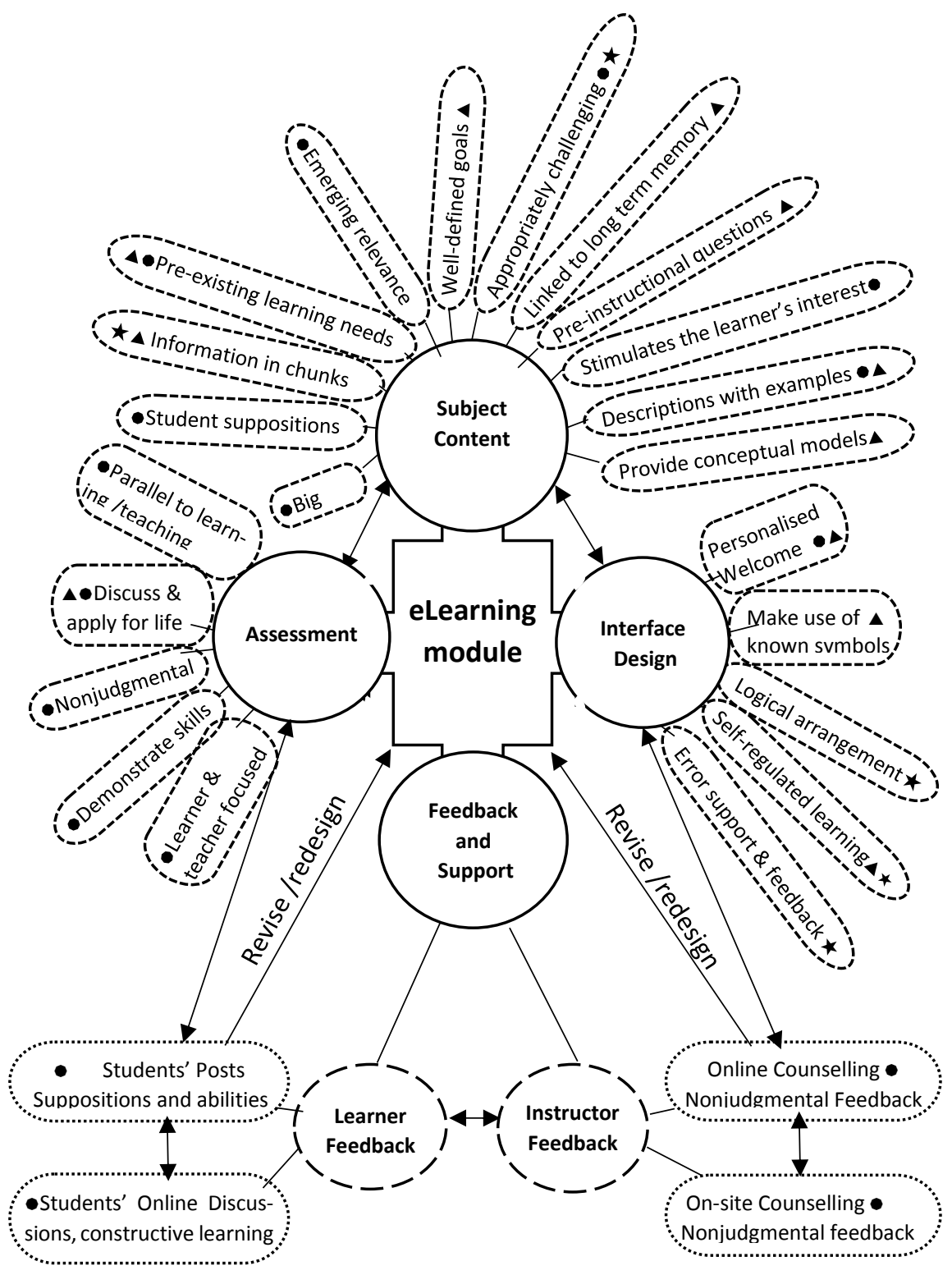

$\star$ Behavioural theory $\Delta$ Social cognitive theory Constructivist learning theory

Fig. 2. A functional model for eLearning design that integrate learning theories: a guide for the designer 
According to this functional model, the subject content of the eLearning module needs to be designed considering learning theories, in order to make the subject content relevant to the learner context as well as to make it accessible.

According to the learning theories, the subject content should be designed considering pre-existing learning needs (need to learn internet functions as identified by Wong et al. [3]), student suppositions (need more clarifications to content with on-site support and/ or videos) and organised with well-defined goals. Social cognitive theory describes that subject content in online learning should be described in small amounts with examples linked to existing memory, to support the learner with limited capacity of working memory [28]. Redesigns for the subject content should be considered according to emerging educational needs with introduction of new technologies, levels of challenge, and how to stimulate the learner's interests.

eLearning designs should follow assessment strategies described in learning theories referring to the learner's context. Constructivist learning theory mentions that assessments should be non-judgemental parallel to teaching and learning, and allow the learner to demonstrate skills learnt and discuss applications in life. Social cognitive theory that emphasises the need of preventing working memory overload during learning, suggests that assessments should occur while the learner practises or applies the skills in real life. In a typical eLearning environment, the learner can be assessed considering the contribution in the form of their posts on activities given, and discussions with peers. Assessment strategies need to be selected according to the learner's background.

In an eLearning environment for people with ID, assessment should be defined as a role of the on-site tutor. Parallel to learning, the on-site tutor observes the learner demonstrating skills, discusses applications of skills, encourages the learner with nonjudgmental feedback on the learner's performance, and identifies redesign needs as a continuous user evaluation of the module. The tutor needs to keep notes on redesign needs according to the learner's performance.

Learning theories that have recommendations on interface design should be followed to make the designs relevant to the learner abilities and to create motivating learning environments. Personalised welcome, as suggested in social cognitive theory and constructivist theory, can be incorporated in eLearning interface design, by providing an introduction to the learning module, referring to the needs of the expected learner, for encouraging them to be engaged with learning. eLearning environments should be designed to be supportive to perform learning activities at the learner's pace, considering the learner's cognitive level.

According to Schunk, some developmental limitations can cause slower responses in self-regulated learning [36]. Hence, social cognitive theory suggests that designs for eLearning modules for people with ID need to include well described content. Multimedia presentations that display skills can be incorporated for the learner to observe, imitate, and improve the self-regulatory skills for a given task. The interface should be designed with the use of known symbols to represent known actions. Such eLearning environments support the learner with limited cognitive skills. Interface designs should provide immediate feedback on the learner's performance, by acknowledging errors 
that have occurred and facilitating corrections to offer an engaging learning environment. Furthermore, these interface designs need to be iteratively redesigned referring to revisions introduced to the content, and suggestions from student and instructor assessments and feedback.

The proposed functional model integrates the learning theories with relevant functions of an eLearning module. It can be used as a guide by designers, as well as by teacherts, to identify applicable strategies, including the modifications described to develop eLearning environments appropriate to the learner context.

\subsection{Guidelines for eLearning Designs for People with Intellectual Disability}

People with ID, having limited cognitive and functional abilities experience difficulties in accessing eLearning environments designed for the general population. Our aim is to describe the applicability of pedagogical theories in designing eLearning environments for increasing accessibility to people with ID. For motivating people with ID to be engaged with eLearning, designs should follow guidelines that strengthen the interactions in an eLearning environment, referring to the learner context.

While learning in an eLearning environment, the learner interacts with subject content, instructor, peers and the interface. The learner should initially learn how to use the interface. Usability deals with presenting the interface in a format that is "easy to learn and remember, effective, and pleasant to use" [37]. Nielsen presents nine heuristics for evaluating user interfaces [38] [39]. Nielsen's heuristics emphasise real conversation, user friendliness, consistent format, instant feedback, effective navigation, expertise benefit, efficient feedback, minimising errors, documented guidance.

Referring to existing literature on usability and instructional approaches, Mehlenbacher et al. presented a heuristic tool for evaluating eLearning environments [40]. Their usability heuristics focussed on the challenges of designing and evaluating eLearning environments. They discuss five dimensions in eLearning design: "the learner's background, knowledge and social dynamics, instructional context, instruction display, instructor activities, and environment and tools". Costabile et al. presents usability criteria and guidelines for eLearning platforms, considering the effectiveness and efficiency of the platform for learning. These guidelines are applicable in eLearning designs. Still, there is a need for eLearning design guidelines that address the context of the learner with ID who needs additional attention on cognitive accessibility and approaches to increase motivation and engagement. As literature suggests, eLearning design guidelines should integrate learning theories with usability criteria for guiding accessible eLearning designs.

Accessibility refers to inclusive design that strengthens interactions between the user and web-based design. Our aim is to present design guidelines that integrate usability principles with theories from learning and pedagogical psychology, and which can be used in inclusive designs of eLearning modules accessible to people with ID. For achieving that aim, we outline a theoretical framework of guidelines for learner 
centered design of eLearning environments for the learners with ID (Fig. 3). The framework models a set of guidelines for interaction design from a learner-centered perspective which accounts for the learner's individuality as well as their interactions.

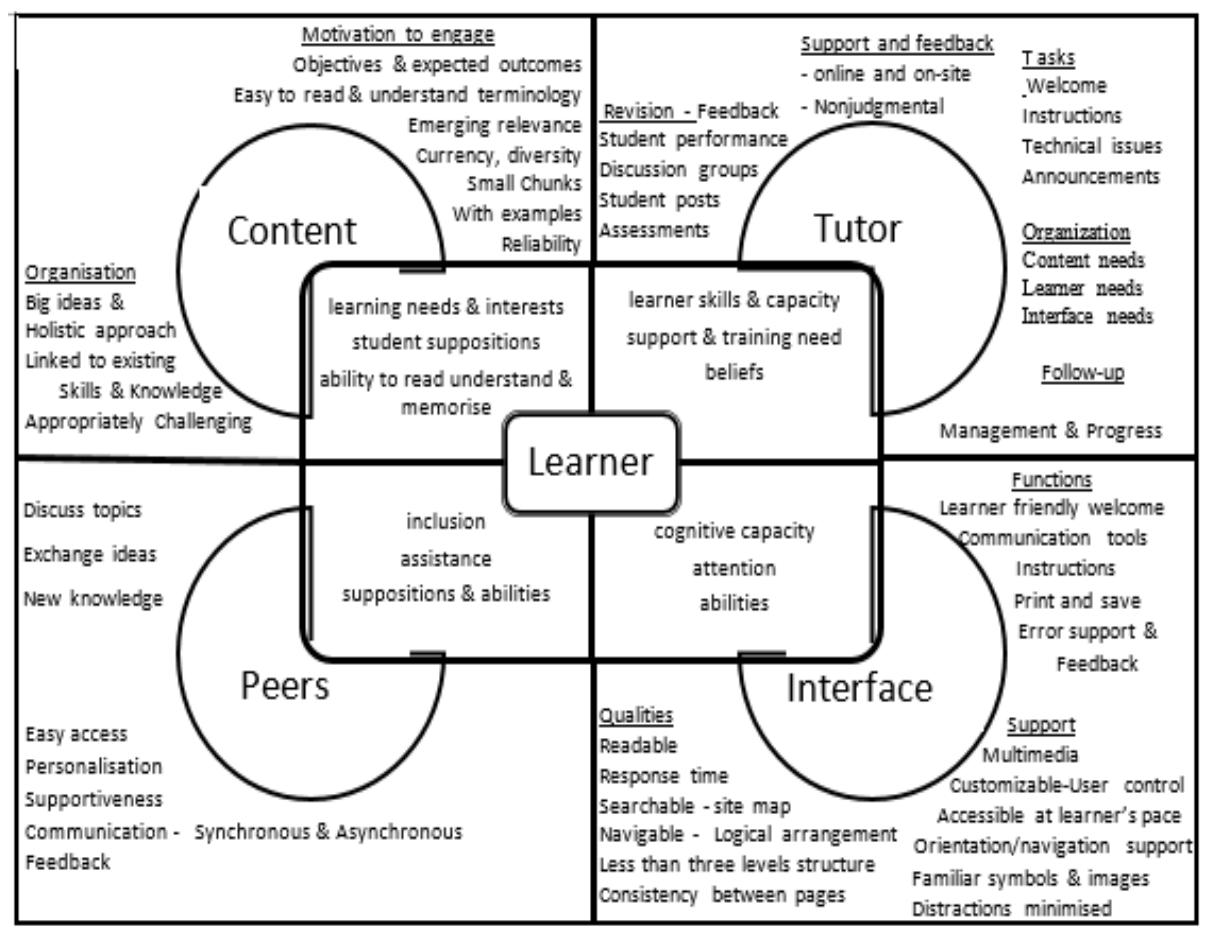

Fig. 3. A theoretical framework of guidelines for learner centered interaction design of eLearning environments for people with intellectual disability

At this point, we describe design guidelines about the subject content and the interface.

Implications for Designing Subject Content. Learner-centered design of subject content should reflect the learner context: their learning needs and interests, their suppositions about learning the proposed content, and ability to read, understand and memorise the content presented in one page. Design guidelines that integrate both usability criteria and learning theories guide this type of design to develop motivating and engaging learning experiences.

The study of the problem situation, needing new eLearning design, creates an understanding of the learner context to be incorporated with the design. This problem analysis should aim to understand the accessibility requirements to make the content learner friendly, easy to understand and relevant. To achieve the identified accessibility requirements in content design, design guidelines should take on board relevant psychological principles about teaching and learning. This suggests that to make eLearning accessible to the learner with intellectual disability, design guidelines should include 
the following principles: make the topics and content appropriately challenging; organise the content around big ideas with a holistic approach; introduce topics with emerging relevance; use content, examples and images linked to existing knowledge and experiences. Emerging relevance can be connected with topics already discussed in the content, learner interests and abilities, new developments in technology and/ or in the discussed subject, and current topics in discussion.

Implications for Designing the Interface. Learner-centered design for the eLearning interface should understand and address the learner context: learner's abilities, cognitive capacity and level of attention. For making eLearning accessible to people with ID, the design should consider the accessibility requirements representing the learner's context.

The eLearning interface design should minimise distractions, maintain consistency, and be easy to operate, read, and navigate. The interface should be supportive, providing quick (response time) and feedback, as well as with personalisation features. Design guidelines regarding accessible eLearning designs for people with ID should include prospects from both learning theories and usability criteria. Referring to learning theories, the eLearning interface should appropriately use known symbols, logical arrangement with a course map and less than three levels structure to enhance navigability. Personalisation by allowing learning at learner's pace, providing options to save the content, make bookmarks, customise fonts, font size, colours and graphics is important to motivate the learner with personalised welcome. eLearning interface should be helpful with immediate and understandable feedback. Usability criteria can be incorporated to guide the eLearning interface design to be accessible by means of minimising distractions. They include avoiding too many graphics, blinking, and animations, four different colours or less, giving priority to the learner's preference about font type and colour, avoiding capital letters, using colours to highlight, and minimising hyperlinks (with acknowledgements that the learner will be directed to a website outside the eLearning module). Considering the learner's capacity to use the mouse to move around, icons and menus should be appropriately large, clues as pop-ups or written words close to the icon should be used to help the learner as necessary. In order to increase the readability and visualisation, suitable font size ( $>14$ point), sentence length ( $<7$ words), and number of sentences per screen $(<4)$ should be decided during an iterative design process. A white background and space between the lines can increase visibility. Each page of the eLearning module should follow a consistent format to help the learner's orientation within the page, minimising the use of cognitive capacity for positioning, and reducing the possibilities for misleads and distractions.

Designing an eLearning module for People with ID needs considerations on their cognitive capacities and abilities. The guidelines we suggest here use learning theories and usability criteria in combination to address the accessibility needs of People with ID, as an approach to guide learner-centered interaction design of eLearning. Table 1 presents the guidelines from a practical standpoint. 
Table 1. Guidelines for learner-centered design of an eLearning environment for learners with intellectual disability

\begin{tabular}{|c|c|c|c|}
\hline $\begin{array}{l}\text { Interac- } \\
\text { tion }\end{array}$ & $\begin{array}{l}\text { Learner } \\
\text { Context }\end{array}$ & $\begin{array}{l}\text { Accessibility } \\
\text { requirement }\end{array}$ & Guidelines \\
\hline \multirow[t]{23}{*}{$\begin{array}{l}\text { Learner - } \\
\text { Interface }\end{array}$} & \multirow[t]{5}{*}{ Attention } & \multirow[t]{5}{*}{$\begin{array}{l}\text { Minimised dis- } \\
\text { tractions }\end{array}$} & $\begin{array}{l}\text { Without too many graphics, blinking, and anima- } \\
\text { tions }\end{array}$ \\
\hline & & & Small number of colours $(<4)$ \\
\hline & & & $\begin{array}{l}\text { Font type and colours appropriate to the learner pref- } \\
\text { erence }\end{array}$ \\
\hline & & & $\begin{array}{l}\text { Highlighting with colour codes instead of capitalisa- } \\
\text { tion of letters }\end{array}$ \\
\hline & & & Minimum Hyperlinks in the content pages \\
\hline & \multirow[t]{2}{*}{ Mobility } & \multirow[t]{2}{*}{ Easy to operate } & Icons and menus large enough to be pointed \\
\hline & & & Prompts and cues to help the learner \\
\hline & \multirow[t]{9}{*}{$\begin{array}{l}\text { Cognitive } \\
\text { capacity }\end{array}$} & \multirow[t]{6}{*}{$\begin{array}{l}\text { Readability \& } \\
\text { Visualisation }\end{array}$} & $\begin{array}{l}\text { Font size according to the user preference }(>14 \\
\text { point) }\end{array}$ \\
\hline & & & Short sentences (<7 words) \\
\hline & & & Minimum number of sentences in one screen $(<4)$ \\
\hline & & & Leave space between lines \\
\hline & & & Use white background \\
\hline & & & $\begin{array}{l}\text { Multimedia, graphics, and images to make the con- } \\
\text { tents familiar and descriptive }\end{array}$ \\
\hline & & \multirow[t]{2}{*}{ Consistency } & $\begin{array}{l}\text { Every screen designed maintaining same format } \\
\text { Consistent positioning of title, menus, forward, back- } \\
\text { ward, print, and save buttons }\end{array}$ \\
\hline & & & Consistency in use of font size and colours \\
\hline & & Feedback & Feedback with error messages and support \\
\hline & \multirow{7}{*}{$\begin{array}{l}\text { Learner } \\
\text { abilities }\end{array}$} & \multirow[t]{4}{*}{ Navigability } & Less than three levels structure \\
\hline & & & $\begin{array}{l}\text { Orientation support by means of logical arrangement, } \\
\text { course map and menus }\end{array}$ \\
\hline & & & Use known symbols \\
\hline & & & Highlight and colour-code the current tasks \\
\hline & & \multirow[t]{3}{*}{ Personalisation } & $\begin{array}{l}\text { Possibility to personalise font size, colours and } \\
\text { graphics }\end{array}$ \\
\hline & & & Possibility to save pages and make bookmarks \\
\hline & & & $\begin{array}{l}\text { Allows learning at the learner's pace; self-regulated } \\
\text { learning }\end{array}$ \\
\hline \multirow[t]{2}{*}{$\begin{array}{l}\text { Learner - } \\
\text { content }\end{array}$} & $\begin{array}{l}\text { Learning } \\
\text { needs and } \\
\text { interests, } \\
\text { Student } \\
\text { suppositions }\end{array}$ & $\begin{array}{l}\text { Easy to under- } \\
\text { stand, } \\
\text { Relevant }\end{array}$ & $\begin{array}{l}\text { Content appropriately challenging } \\
\text { Content organised around big ideas with holistic ap- } \\
\text { proach } \\
\text { Topics introduced in immerging relevance } \\
\text { Content, examples and images linked to existing } \\
\text { skills and knowledge }\end{array}$ \\
\hline & $\begin{array}{l}\text { Ability to } \\
\text { read and } \\
\text { memorise }\end{array}$ & $\begin{array}{l}\text { Learner } \\
\text { friendly }\end{array}$ & $\begin{array}{l}\text { Content in easy to read and easy to understand termi- } \\
\text { nology } \\
\text { Content presented on small chunks } \\
\text { Explained with examples including images and or } \\
\text { multimedia }\end{array}$ \\
\hline
\end{tabular}




\section{A Design for an eLearning Module for People with Intellectual Disability: a Case Study}

We apply these guidelines in designing an eLearning module to increase the abilities of people with ID to be included in online information. The eLearning module describes and teaches how to access health information. It offers the user an opportunity to improve skills needed to use the Internet while learning in the practical environment, navigating between pages and the units of the module.

One unit of that module is about describing for the learner, how to find a Medical Centre close by, and then identifying the link for making an appointment. In the meantime, the learner becomes familiar with two other types of information: location and the opening hours of the Medical Centre. The two screens of the prototype we designed are presented in Fig. 4 and Fig. 5 respectively. This eLearning module does not include an assessment. Instead, a tutor, who gives on-site support to the learner, observes the learner's behaviour during learning and gives non-judgemental feedback, to encourage engagement with learning.

We adopted the following key guidelines while designing the content of our prototype.

- Content in small chunks/units

- Outline in the first screen

- Easy to read terminology

- One point in one screen

- Relevant learning tasks

- Few examples to familiarise

- Questions to ask from peers

- Big ideas for teaching skills to use internet

- Online searching

○ Web search engine can be used to find a website

- Navigation and orientation

○ Menu helps to navigate in a website

$\circ$ Links direct to a new website

- Forward and backward buttons to go to next and previous pages

- Communication

○ The Internet delivers messages

We adopted the following key guidelines while designing the interface of our prototype.

- Video with introduction

- Content to be printed

- Make icons large

- Menu in every page

- Instant feedback
- Minimise distractions

- Simple and understandable

- Sitemap help orientation

- Audio descriptions to content 


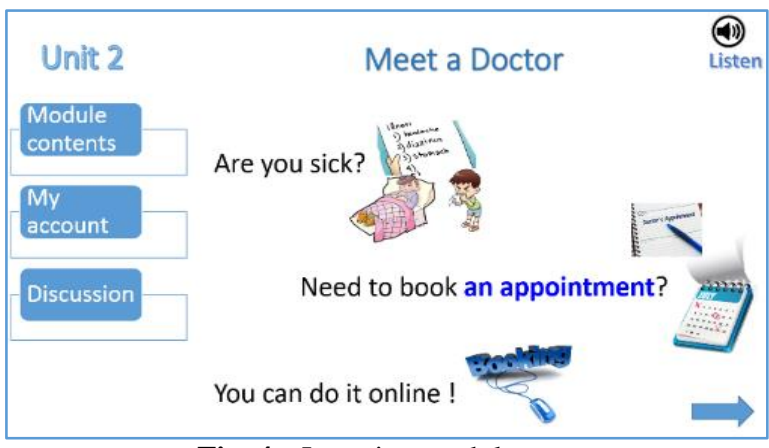

Fig. 4. eLearning module screen

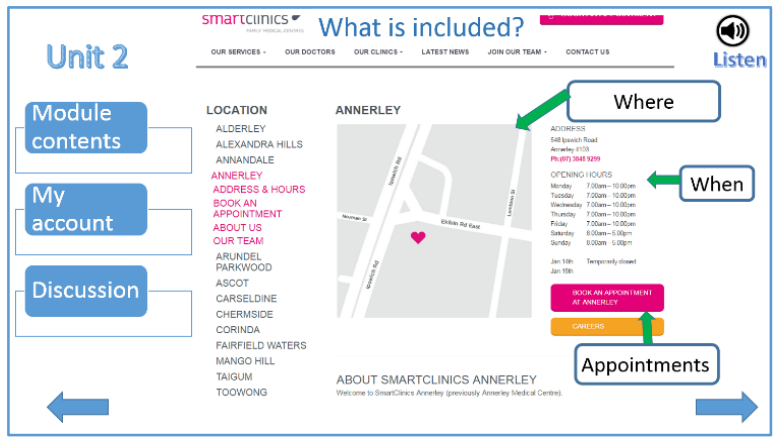

Fig. 5. eLearning module screen

We have divided the module into small units. For example, one of them, which we describe here, includes eight screens. Each screen includes a small amount of information, and can be viewed without scrolling. The screen in fig. 4 includes only three sentences, which comprise thirteen words. The content is described in simple language. Referring to the learners' cognitive capacity, contents have been further clarified with examples and images. Use of several examples for clarifying one term aims at making it familiar to most. Furthermore, the content is arranged in logical order. The first page of our prototype (Fig. 4) includes a topic that describes the goal of the unit, "Meet a doctor". Then it describes the background, and extends to the objective of the unit; learn how to make an appointment online, instead of mentioning it as a single sentence "This unit aims to teach you, how to make an appointment for meeting a doctor when you are sick".

We have used different screens to discuss different sub topics: entering key words to search, using the search results page etc. Each of these subtopics has been described with two examples that search for two different Medical Centre websites and familiarise with links to online appointments, opening hours and the location of each Medical Centre (Fig. 5). Each unit introduces questions that support them to discuss what they learnt from the unit. For example, the unit we describe here gives a question to find a 
Medical Centre close to them, and find the link to make online appointments, the location of the Medical Centre, and opening hours.

Learning tasks have been selected for the learner to develop navigation and online searching skills as well as the ability to communicate with others using Internet, referring to their existing skills and preferences. This module helps them to experience how a menu and the forward and backward buttons work, as they use the module to learn how to access online health information. They also experience how the link from the search results directs them to a website. The opportunity to make an appointment online explains to them that the Internet can deliver their request to the Medical Centre.

In each page, we presented large icons for better and improved visibility. We included menu buttons, back and forward buttons, and an icon to access audio, which are large enough as well. The menu and the other icons have been included in every page in the same position. We have not included animations and blinking pictures to minimise distractions. We have made the screen designs simple and understandable, consistently using the same format. The menu guides the learner to navigate through the module. Furthermore, we have used a known symbol, with a description word "Listen" to encourage its use. Font size and colours have been selected to personalise the interface to the learner. Each screen of the unit prepares the learner to learn the next screen.

\section{Conclusion}

Designing accessible eLearning modules requires careful attention to technological usability as well as the psychological appropriateness of the teaching material presented. This article suggests eLearning design guidelines that consider principles of teaching and learning along with usability criteria to address the learner's needs. First, we have presented learning theories that relate to the four elements of an eLearning environment: content, interface, assessments, and feedback. We incorporated the learning and teaching strategies into a theoretical framework of guidelines for learner-centered interaction design of eLearning modules for people with ID. Then, we used that framework to establish the guidelines for eLearning module design. Finally, we presented a concrete example of the application of the guidelines through a case study.

This paper focuses on the content and interface design. That is, we have not addressed the learner-teacher interactions and the learner-peers interactions. In future work, we will further explore these interactions, and the role of on-site support people to determine how universal designs of eLearning platforms should account for their contributions and requirements.

Acknowledgements . The authors would like to thank the anonymous reviewers and editors from INTERACT 2017 for their very much helpful comments on the previous version of this paper. The authors wish to acknowledge the University Grant Commission, Sri Lanka, University of Colombo and Queensland University of Technology for their support for this research study. 


\section{Reference List}

1. Harrysson, B., A. Svensk, and G.I. Johansson, How people with developmental disabilities navigate the Internet. British Journal of Special Education, 2004. 31(3): p. 138-142.

2. Rocha, T., et al. Accessibility and usability in the internet for people with intellectual disabilities. in Proceedings of 2nd International Conference on Software Development for Enhancing Accessibility and Fighting Info-exclusion-DSAI. 2009.

3. Wong, A.W.K., et al., Competence of people with intellectual disabilities on using human-computer interface. Research in Developmental Disabilities, 2009. 30(1): p. 107-123.

4. Sitbon, L., et al. Towards universal search design. in Proceedings of the 2014 Australasian Document Computing Symposium. 2014. ACM.

5. Standen, P. and D. Brown, Using virtual environments with pupils with learning difficulties, in ICT and Special Educational Needs: A Tool for Inclusion, L.F.a.J. Hegarty, Editor. 2004, Open University Press: Berkshire. p. 96-108.

6. Mayes, T. and S. de Freitas, Learning and e-learning. Rethinking pedagogy for a digital age, 2007: p. 13.

7. Standen, P.J., D.J. Brown, and J.J. Cromby, The effective use of virtual environments in the education and rehabilitation of students with intellectual disabilities. British Journal of Educational Technology, 2001. 32(3): p. 289-299.

8. Kolb, D.A., Experiential learning: Experience as the source of learning and development. 1984, New Jersey: Prentice-Hall, Inc.

9. Victoria, Intellectually Disabled Persons Services Act 1986. 1987: Melbourne, Vic.

10. National Definition of Learning Disabilities Adopted by the Learning Disabilities Association of Canada (January 30, 2002). 2015; Available from: http://www.ldacacta.ca/learn-more/ld-defined/official-definition-of-learning-disabilities.

11. Melis, E., M. Weber, and E. Andrès. Lessons for (pedagogic) usability of eLearning systems. in Proceedings of World Conference on E-Learning in Corporate, Government, Healthcare, and Higher Education (Chesapeake, VA, USA,). Ed. by A. Rossett. AACE, pp.-.(Cit. on p.). 2003.

12. Henry, S.L. Introduction to Web Accessibility: Web accessibility initiative (WAI) W3C 2005; Available from: https://www.w3.org/WAI/intro/accessibility.php.

13. Squires, D., Usability and educational software design: special issue of interacting with computers. Interacting with Computers, 1999. 11(5): p. 463-466.

14. Maldonado, U.P.T., et al. E-learning motivation, Students' Acceptance/Use of Educational Portal in Developing Countries: A Case Study of Peru. in 2009 Fourth International Conference on Computer Sciences and Convergence Information Technology. 2009.

15. Seo, Y.-J. and H. Woo, The identification, implementation, and evaluation of critical user interface design features of computer-assisted instruction programs in mathematics for students with learning disabilities. Computers \& Education, 2010. 55(1): p. 363-377.

16. Harris, J.C., Intellectual disability: Understanding its development, causes, classification, evaluation, and treatment. 2006: Oxford University Press. 
17. Renblad, K., How do people with intellectual disabilities think about empowerment and information and communication technology (ICT)? International Journal of Rehabilitation Research, 2003. 26(3): p. 175-182.

18. Ogunbase, A.O., Pedagogical Design and Pedagogical Usability of Web-based Learning Environments: Comparative Cultural Implications between Africa and Europe, in School of Information Sciences. 2016, University of Tampere: Tampere.

19. Li-Tsang, C.W.P., et al., A 6-month follow-up of the effects of an information and communication technology (ICT) training programme on people with intellectual disabilities. Research in Developmental Disabilities, 2007. 28(6): p. 559-566.

20. Bunning, K., B. Heath, and A. Minnion, Interaction between teachers and students with intellectual disability during computer-based activities: The role of human mediation. Technology and Disability, 2010. 22(1, 2): p. 61-71.

21. Mayes, J.T. and C.J. Fowler, Learning technology and usability: a framework for understanding courseware. Interacting with computers, 1999. 11(5): p. 485-497.

22. Snowman, J. and R. Biehler, Psychology Applied to Teaching. 2006, Boston: Houghton Mifflin Company

23. Schunk, D.H., Learning theories. Printice Hall Inc., New Jersey, 1996.

24. APA. Learner-Centered Psychological Principles: A Framework for School Reform \& Redesign. 1997; Available from: https://www.apa.org/ed/governance/bea/learnercentered.pdf.

25. Skinner, B.F., Operant behavior. American Psychologist, 1963. 18(8): p. 503.

26. Skinner, B.F., The shame of American education. American Psychologist, 1984. 39(9): p. 947.

27. Bandura, A., Social foundations of thought and action: A social cognitive theory. 1986: Prentice-Hall, Inc.

28. Anderson, T., The theory and practice of online learning. 2008: Athabasca University Press.

29. Bruner, J.S., The act of discovery. Harvard educational review, 1961. 31: p. 21-32.

30. Brooks, J.G. and M.G. Brooks, In search of understanding: The case for constructivist classrooms. 1999: ASCD.

31. Garrison, R., Implications of Online Learning for the Conceptual Development and Practice of Distance Education. REVUE DE L'ÉDUCATION À DISTANCE, 2009. 23(2): p. 93-104.

32. Anderson, T., Getting the mix right again: An updated and theoretical rationale for interaction. The International Review of Research in Open and Distributed Learning, 2003. 4(2).

33. Metros, S.E. and J.G. Hedberg, MORE THAN JUST A PRETTY (INTER) FACE: The Role of the Graphical User Interface in Engaging eLearners. Quarterly Review of Distance Education, 2002. 3(2): p. 191.

34. Fryia, G.D., R. Wachowiak-Smolikova, and M.P. Wachowiak. Human-computer interface design in an e-Learning system for individuals with cognitive and learning disabilities. in Digital Information Management, 2009. ICDIM 2009. Fourth International Conference on. 2009. IEEE.

35. Hillman, D.C., D.J. Willis, and C.N. Gunawardena, Learner-interface interaction in distance education: An extension of contemporary models and strategies for practitioners. American Journal of Distance Education, 1994. 8(2): p. 30-42. 
36. Zimmerman, B.J. and D.H. Schunk, Self-regulated learning and academic achievement: Theoretical perspectives. 2001: Routledge.

37. Molich, R. and J. Nielsen, Improving a human-computer dialogue. Commun. ACM, 1990. 33(3): p. 338-348.

38. Nielsen, J., Enhancing the explanatory power of usability heuristics, in Proceedings of the SIGCHI Conference on Human Factors in Computing Systems. 1994, ACM: Boston, Massachusetts, USA. p. 152-158.

39. Nielsen, J. and R. Molich, Heuristic evaluation of user interfaces, in Proceedings of the SIGCHI Conference on Human Factors in Computing Systems. 1990, ACM: Seattle, Washington, USA. p. 249-256.

40. Mehlenbacher, B., et al. Usable e-learning: A conceptual model for evaluation and design. in Proceedings of HCI International 2005: 11th International Conference on Human-Computer Interaction. 2005. 